\title{
Electrochemical Determination of Caffeine in Tea Using a Polydopamine-Gold Nanocomposite
}

\author{
Guolin Zhang ${ }^{1,3}$, Haiping $\mathrm{Fu}^{2 \dagger}$, Dongsheng Zou ${ }^{1, *}$, Runlin Xiao ${ }^{3}$, Jun Liu ${ }^{4}$ and Shaojing $\mathrm{Li}^{4}$ \\ ${ }^{1}$ College of Bioscience and Biotechnology, Hunan Agricultural University, Changsha, 410128, P.R. \\ China \\ ${ }^{2}$ Tea Research Institute of Hunan Academy of Agricultural Science, Changsha, 410125, P.R. China \\ ${ }^{3}$ The Institute of Subtropical Agriculture, The Chinese Academy of Sciences, Changsha, 410125, P.R. \\ China \\ ${ }^{4}$ Qingdao Engineering Research Center for Rural Environment, Qingdao Agricultural University, \\ Qingdao, 266109, P.R. China \\ Co-first author \\ *E-mail: dongshengzouBio@foxmail.com
}

doi: $10.20964 / 2017.12 .76$

Received: 17 August 2017 / Accepted: 7 October 2017 / Published: 12 November 2017

\begin{abstract}
A polydopamine-gold nanocomposite (PDA/AuNPs)-based caffeine sensor with high sensitivity was fabricated. The electrochemical performance of the caffeine sensor was characterized in various electrolyte solutions, including sodium perchlorate, phosphate buffer saline, and choline chloride containing oxalic acid. The influence of interference agents, normally present in caffeine-containing samples, on caffeine detection was also studied. The PDA/AuNPs/GCE-based sensor showed excellent performance in the determination of caffeine in tea samples.
\end{abstract}

Keywords: Caffeine; Electrochemical sensor; Graphene; Polydopamine; Children asthmatic attack

\section{FULL TEXT}

(C) 2017 The Authors. Published by ESG (www.electrochemsci.org). This article is an open access article distributed under the terms and conditions of the Creative Commons Attribution license (http://creativecommons.org/licenses/by/4.0/). 